\title{
Desempenho produtivo de juvenis de tambaqui (Colossoma macropomum CUVIER, 1818) alimentados com rações contendo farinha de crueira de mandioca (Manihot esculenta, CRANTZ) em substituição ao milho (Zea mays)
}

Geraldo Pereira PEREIRA JUNIOR ${ }^{1}$, Expedita Maria de Oliveira PEREIRA ${ }^{2}$, Manoel Pereira FILHO ${ }^{3}$, Paula de Sousa BARBOSA ${ }^{4}$, Eduardo SHIMODA ${ }^{5}$, Lian Valente BRANDÁO ${ }^{6}$

\section{RESUMO}

O objetivo deste estudo foi avaliar o desempenho produtivo de juvenis de tambaqui (Colossoma macropomum), alimentados com níveis crescentes de farinha de crueira de mandioca, Manihot esculenta (0\%,20\%, 40\%,60\%, 80\%, 100\%), como substituto do milho (Zea mays). Os peixes (peso médio inicial de 6,6 $\pm 0,1 \mathrm{~g}$ ) foram distribuídos aleatoriamente em 24 grupos (20 peixes/grupo) e alimentados com as dietas experimentais em quatro repetições para avaliação da performance de crescimento, eficiência alimentar, composiçáo corporal e os custos de produçáo. As performances de crescimento não foram afetados pelos tratamentos. O teor de lipídio no músculo foi diferentemente significativo em peixes alimentados com 40\% e 100\% em relação aos outros tratamentos. $\mathrm{O}$ custo de produção de milho diminuiu linearmente com a substituição. $\mathrm{O}$ valor da dieta diminuiu de $\mathrm{R}$ \$ $1,43 \mathrm{~kg}^{-1}$ a $\mathrm{R}$ \$1,21 $\mathrm{kg}^{-1}$ e o peixe de $\mathrm{R}$ \$ 1,54 $\mathrm{kg}^{-1}$ a $\mathrm{R}$ \$ 1,30 peixe $\mathrm{kg}^{-1}$. Concluiu-se que o milho pode ser totalmente substituído por farinha de crueira de mandioca na dieta de juvenil de tambaqui, sem prejudicar o seu desempenho.

PALAVRAS CHAVE: Piscicultura, nutrição de peixes, carboidratos.

\section{Performance of juvenile tambaqui (Colossoma macropomum Cuvier, 1818) fed diets containing crueira manioc flour (Manihot esculenta, Crantz) in replacement of corn (Zea mays)}

\section{ABSTRACT}

The main objective of this study was to evaluate the productive performance of young tambaqui (Colossoma macropum), fed with increasing levels of cassava flour, Manihot esculenta $(0 \%, 20 \%, 40 \%, 60 \%, 80 \%, 100 \%)$, as corn (Zea mays) replacement. Fish (initial body weight $6.6 \pm 0.1 \mathrm{~g}$ ) were randomly distributed in 24 groups ( 20 fish/group) with four replications. They were fed with the experimental diets for evaluation of growth performances, feed utilization, body composition and production costs. Growth performances were not affected by the dietary treatments. Lipid content in muscle were significant different in fish fed $40 \%$ and $100 \%$ substitution when compared to the other treatments. The production cost decreased linearly with corn substitution. Diet decreased from $\mathrm{R} \$ 1.43 \mathrm{~kg}^{-1}$ to $\mathrm{R} \$ 1.21 \mathrm{~kg}^{-1}$ and fish production cost from $\mathrm{R} \$ 1.54 \mathrm{~kg}^{-1}$ to $\mathrm{R} \$ 1.30$ $\mathrm{kg}^{-1}$ fish. It was concluded that the corn can be totally replaced by cassava flour in juvenile tambaqui diet without adversely affecting the performance of tambaqui.

KEYWORDS: Fish farming, fish nutrition, carbohydrates.

\footnotetext{
geraldoinpa@hotmail.com

2 expedita@ufam.edu.br

3 pmanoel@inpa.gov.br

4 manatee_psbd@hotmail.com

${ }^{5}$ shimoda@ucam-campos.br

6 lianpesca@yahoo.com.br
} 


\section{INTRODUÇÃO}

Para as populações que vivem na regiāo amazônica, o peixe é a principal fonte de proteína de origem animal disponível, representando também uma fonte de renda para os pescadores (Araújo-Lima e Goulding 1998). Entretanto, o intenso crescimento da população na região Norte tem aumentado a demanda por pescado e gerado maior pressáo sobre os estoques naturais, diminuindo a quantidade de peixes capturados e elevando o preço das espécies preferidas para consumo (Batista e Petrere 2003). Diante desta problemática, a piscicultura regional apresenta-se como uma atividade com potencial para minimizar os efeitos da exploração predatória de algumas espécies de maior valor econômico (Cheng et al. 2003).

Inúmeros fatores contribuem para que a piscicultura seja a atividade zootécnica de maior potencialidade na região amazônica. Dentre estes, podem ser mencionadas a quantidade de recursos hídricos disponíveis (Batista et al. 2004), a boa qualidade das águas (Arbelaez-Rojas et al. 2002), as características físicas dos solos, a disponibilidade de mão de obra, mercado consumidor em expansão e a quantidade de espécies de peixes com potencial para criação em ambientes artificiais (Val 1995).

Entre as espécies de peixes nativos com potencial para cultivo em cativeiro destaca-se o tambaqui (Colossoma macropomum), por apresentar diversas características desejáveis, tais como: disponibilidade de juvenis para comercialização durante o ano todo (Rolim 1995), hábito alimentar diversificado (Silva et al. 1991), rápido crescimento, boa conversão alimentar (Val et al. 1998), resistência a baixos níveis de oxigênio dissolvido na água (Graef 1995) e boa aceitação pelos consumidores (Hancz 1993). Segundo Batista et al. (2004), esta é a espécie amazônica mais criada em todo território brasileiro.

Entretanto, para se obter bons resultados em cultivos comerciais de peixes o alimento fornecido para as espécies devem conter todos os nutrientes necessários para o bom desenvolvimento (Pereira Filho 1995). Este mesmo autor chama a atenção para os custos com a alimentação dos peixes, que podem corresponder de 60 a $80 \%$ dos custos totais de produção. Geralmente, os nutrientes mais caros em dietas para organismos aquáticos são a proteína e a energia, sendo suas principais fontes a farinha de peixe e o milho, respectivamente (Santos et al. 2009).

Os estudos que avaliam a substituição total ou parcial dos ingredientes comumente utilizados em raçóes para peixes comerciais por ingredientes alternativos são de suma importância por viabilizar a elaboração de dietas com menor custo sem perder a eficiência nutricional (Boonyaratpalin $e t$ al. 1998). Essa importância fica evidente na regiâo amazônica, onde existe a necessidade de importação de ingredientes de outras regiốes para elaboração de raçôes, elevando o custo final do produto. Sendo assim, a inclusáo de produtos regionais em dietas para peixes tem sido amplamente investigada na região amazônica (Ximenes-Carneiro 1991; Roubach e SaintPaul 1994; Mori-Pinedo et al. 1999), demonstrando que a identificação de fontes alternativas de alimento é indispensável para o desenvolvimento da piscicultura na regiáo amazônica.

Dentre os ingredientes alternativos para compor raçóes para peixes, destacam-se os subprodutos da mandioca (Santos et al. 2009), a exemplo da crueira. Este subproduto é obtido na fabricação de farinha da raiz de mandioca, durante a etapa de peneiramento da massa. Por ser composta de entrecascas, fiapos e cepas, a crueira de mandioca possui diâmetro maior do que a malha da peneira, ficando retida durante o peneiramento (Tagliari 1996). Apesar de não existirem dados absolutos a respeito da quantidade produzida deste resíduo, estima-se que $10 \%$ da mandioca utilizada na fabricação de farinha é eliminada na forma de crueira (Cereda 1994).

Análises centesimais demonstraram que a crueira, assim como outros subprodutos da farinha de mandioca, possui grande quantidade de carboidrato (93,7\%) e baixa quantidade de proteína bruta $(1,7 \%)$, sendo um alimento energético com potencial de utilização em raçóes para animais (Guimarães et al. 2011). Apesar do potencial dos subprodutos da mandioca na alimentação de animais, poucos são os trabalhos que testaram a inclusão destes ingredientes em raçóes para peixes.

Lacerda et al. (2005) substituíram o milho pelo farelo de mandioca em raçôes para alevinos de carpa capim e verificaram que os índices zootécnicos não foram influenciados pelos diferentes teores de inclusão do farelo de mandioca, o que permitiu afirmar que esse alimento não apresenta problemas quanto a aceitabilidade pela carpa-capim e que os peixes aproveitam tâo bem seus nutrientes quanto os do milho sem implicaçóes na digestibilidade das raçóes. Resultados semelhantes foram observados para tilápia Oreochromis niloticus, alimentadas com ração contendo farinha de varredura de mandioca (Boscolo et al. 2002) e para pacu (Piaractus mesopotamicus), alimentados com rama de mandioca (Pádua et al. 2009).

Diante do exposto, o objetivo deste trabalho foi avaliar o desempenho produtivo de juvenis de tambaqui alimentados com raçôes contendo farinha de crueira de mandioca em substituição ao milho.

\section{MATERIAL E MÉTODOS}

O experimento foi conduzido no galpão experimental da Coordenação de Pesquisas em Aquicultura - CPAQ/INPA. O experimento foi realizado no período de outubro de 2008 até janeiro de 2009, com duração de 75 dias. 
Durante o período experimental foram aferidos os parâmetros de qualidade da água, sendo realizadas a cada sete dias, medidas de amônia ([média \pm desvio]), nitrito ([média \pm desvio]), gás carbônico, dureza ([média \pm desvio]) e alcalinidade ([média \pm desvio]) através dos métodos de colorimetria (amônia e nitrito) e titulaçáo (gás carbônico, dureza e alcalinidade). A cada dois dias os teores de oxigênio dissolvido foi avaliado através de um oxímetro digital e as medidas de temperatura ([média \pm desvio]) e $\mathrm{pH}$ ([média \pm desvio]) foram aferidas com um peagâmetro digital.

As raçôes foram formuladas de modo a serem isoprotéicas (36\% PB) e isocalóricas (3500 kcal ED/kg) (tabela 1) com níveis crescentes $(0,20,40,60,80$ e 100\%) de substituição do milho por farinha de crueira, sendo os grupos denominados como: controle, I, II, III, IV e V, respectivamente. Para formulação das raçôes experimentais foi utilizado o programa Super Crac (software para formulação de raçôes, $1^{\circ}$ versão, desenvolvido pela Universidade Federal de Viçosa - UFV).

A crueira de mandioca utilizada no experimento foi obtida em casa de farinha artesanal. Por se tratar de um produto úmido

Tabela 1 - Composição percentual dos ingredientes e características nutritivas das dietas experimentais com diferentes níveis de substituição do milho por farinha de crueira de mandioca (Manihot esculenta)*

\begin{tabular}{|c|c|c|c|c|c|c|}
\hline \multirow{2}{*}{ Ingredientes } & \multicolumn{6}{|c|}{ Níveis de substituição da farinha de crueira (\%) } \\
\hline & 0 & 20 & 40 & 60 & 80 & 100 \\
\hline Milho & 30,0 & 24,0 & 18,0 & 12,0 & 6,0 & 0,0 \\
\hline Farinha de crueira & 0,0 & 6,0 & 12,0 & 18,0 & 24,0 & 30,0 \\
\hline Óleo de soja & 3,6 & 3,7 & 3,4 & 3,6 & 3,2 & 3,6 \\
\hline Farelo de soja & 55 & 54 & 52,7 & 49,8 & 50,0 & 45,8 \\
\hline $\begin{array}{l}\text { Farelo de glúten de } \\
\text { milho }\end{array}$ & 2,0 & 2,0 & 3,6 & 7,0 & 7,0 & 10,0 \\
\hline $\begin{array}{l}\text { Farinha de carne e } \\
\text { ossos }\end{array}$ & 3,0 & 3,0 & 3,0 & 3,0 & 3,0 & 4,0 \\
\hline Farinha de peixe & 3,0 & 3,0 & 3,0 & 3,0 & 3,0 & 3,0 \\
\hline Fosfato bicálcico & 2,0 & 2,8 & 2,8 & 2,3 & 2,3 & 2,1 \\
\hline DL-metionina & 0,35 & 0,35 & 0,35 & 0,32 & 0,43 & 0,4 \\
\hline Premix & 1,0 & 1,0 & 1,0 & 1,0 & 1,0 & 1,0 \\
\hline Total & 100,0 & 100,0 & 100,0 & 100,0 & 100,0 & 100,0 \\
\hline \multirow{2}{*}{ Nutrientes (\%) } & \multicolumn{6}{|c|}{ Níveis de substituição da farinha de crueira (\%) } \\
\hline & 0 & 20 & 40 & 60 & 80 & 100 \\
\hline Matéria seca (\%) & 93,0 & 94,2 & 93,5 & 93,5 & 94,1 & 94,2 \\
\hline Proteína bruta (\%) & 38,3 & 36,9 & 37,7 & 37,6 & 36,7 & 36,7 \\
\hline Extrato etéreo (\%) & 3,6 & 4,4 & 3,9 & 3,8 & 3,4 & 4,4 \\
\hline Cinzas (\%) & 7,3 & 7,8 & 8,0 & 7,6 & 7,5 & 7,2 \\
\hline Fibra bruta (\%) & 1,8 & 2,2 & 2,7 & 2,8 & 2,8 & 3,1 \\
\hline ENN (\%) & 42,0 & 42,9 & 41,2 & 41,7 & 43,7 & 42,8 \\
\hline Energia bruta $(\mathrm{Kcal} / \mathrm{kg})^{\star}$ & 4225 & 4259 & 4187 & 4191 & 4185 & 4243 \\
\hline EB:PB & 11,0 & 11,5 & 11.1 & 11,1 & 11,4 & 11,5 \\
\hline
\end{tabular}

$\mathrm{ENN}=$ extrativo não nitrogenado; $\mathrm{EB}=$ energia bruta; $\mathrm{PB}=$ proteína bruta *Calculado segundo NRC 1993 ela foi desidratada em estufa a $60{ }^{\circ} \mathrm{C}$, por 48 horas, sendo posteriormente moída em moinho tipo martelo, com matriz fina de 0,8 milímetros. Para uniformização das partículas, todos os outros ingredientes utilizados na composiçấo das raçóes passaram pelo mesmo processo de moagem.

Para o preparo das dietas experimentais todos os ingredientes foram misturados e processados em uma extrusora de rosca simples, com condicionador duplo e injeção de água (INBRAMAQ, modelo MX80), com velocidade de rosca constante e com matriz de $5 \mathrm{~mm}$, para formação dos grânulos. Estes foram desidratados em estufa a uma temperatura de 60 ${ }^{\circ} \mathrm{C}$, por 48 horas. As raçôes foram acondicionadas em sacos plásticos de $2 \mathrm{~kg}$ e mantidas em freezer a $5^{\circ} \mathrm{C}$ negativos.

Para a determinação dos índices zootécnicos foram utilizados 480 juvenis de tambaqui com peso inicial médio de 6,6 $\pm 0,1$ g distribuídos aleatoriamente em 24 unidades experimentais (seis tratamentos com quatro repetiçóes). Cada unidade experimental foi representada por uma caixa plástica redonda, com capacidade para 350 litros, abastecida com água de poço artesiano, renovação diária (10\% do volume) e aeração constante. Após um período de adaptaçáo às condiçóes experimentais de setes dias, onde as unidades foram alimentadas com dieta contendo $36 \% \mathrm{~PB}$, os animais passaram por um jejum de um dia para, posteriormente, serem alimentados três vezes ao dia (às 9:00, 13:00 e 17:30h) com as raçôes testadas, até a saciedade aparente.

Ao longo desta fase experimental foram realizadas três biometrias, uma realizada no início do experimento, a segunda aos 35 dias e a última aos 75 dias de avaliação experimental. Estas últimas possibilitaram avaliar o efeito de cada ração sobre o desempenho dos peixes. Para reduzir os efeitos de estresse durante a manipulação dos peixes, foi usada uma soluçáo com anestésico benzocaína, $100 \mathrm{mg} \mathrm{L}^{-1}$ de água (Gomes et al. 2001).

O desempenho dos peixes foi avaliado em termos de ganho de peso (Gp, g), comprimento final (cm), índice de conversão alimentar $\left(\mathrm{CA}, \mathrm{g} \mathrm{g}^{-1}\right)$, taxa de crescimento diário (TCD, \% biomassa/ dia), eficiência aparente de conversão protéica (CPa, \% proteína), fator de condição $(\mathrm{k})$ e sobrevivência (\%). Os parâmetros de desempenho foram calculados de seguinte forma: $G p=P_{i}-P_{f}(g), P_{i}$ é o peso inicial dos peixes e $P_{f}$ é o peso final dos peixes no dia $\mathrm{t} ; \mathrm{CA}=$ consumo da dieta $(\mathrm{g}) /$ ganho de peso $(\mathrm{g})$; TCD $=100 \times\left(\mathrm{P}_{\mathrm{f}}^{1 / 3}-\mathrm{P}_{\mathrm{i}}^{1 / 3}\right) / \mathrm{t}$; sendo $\mathrm{t}$ a duraçáo do ensaio de alimentaçấo $(t=75$ dias $), C P a=100 x$ (ganho protéico, g) / (consumo protéico, g); $\mathrm{k}=(\mathrm{Px} 100) \mathrm{C}^{-3}$, sendo $\mathrm{P}$ o peso em $\mathrm{kg}$ e $\mathrm{C}$ o comprimento em $\mathrm{cm}$.

Para determinar o efeito das dietas experimentais sobre a composição centesimal da carcaça, antes da formaçáo das unidades experimentais 10 juvenis de tambaqui foram aleatoriamente retirados do lote base, sacrificados e congelados 
para posterior análise, compondo a composiçáo centesimal da carcaça inicial. Ao final do experimento, três indivíduos por unidade experimental foram escolhidos ao acaso para a determinação da composiçấo centesimal final da carcaça.

Os teores de umidade, proteína bruta, extrato etéreo, fibra bruta e cinzas dos ingredientes, das dietas e das carcaças foram determinados segundo metodologia descrita pela AOAC (1997).

$\mathrm{O}$ valor do extrato não-nitrogenado (carboidratos) foi calculado segundo a fórmula proposta pela AOAC (1997), em que: Extrativo não nitrogenado $(\mathrm{ENN})=100-$ (umidade + proteína bruta + extrato etéreo + fibra etéreo + cinzas).

A Energia bruta foi estimada com base nos valores calculados de energia para proteína $=5,64 \mathrm{Kcal} \mathrm{g}^{-1}$, extrato etéreo $=9,44 \mathrm{Kcal} \mathrm{g}^{-1} \mathrm{e}$ extrato não-nitrogenado $=4,11 \mathrm{Kcal}$ $\mathrm{g}^{-1}$ (NRC 1993).

Para avaliar a influência da substituição do milho pela farinha de crueira de mandioca no custo produtivo, foi determinado o custo médio do alimento por quilograma de peso vivo ganho, segundo Bellaver et al. (1985).

\section{$\mathrm{Yi}=\mathrm{Qi} \times \mathrm{Pi} / \mathrm{Gi}$}

Em que: $\mathrm{Yi}$ = custo médio da ração por quilograma ganho no i-ésimo tratamento, $\mathrm{Q} i=$ quantidade média de ração consumida no i-ésimo tratamento, $\mathrm{Pi}=$ preço médio por quilograma de ração utilizada no i-ésimo tratamento, $\mathrm{Gi}$ = ganho médio de peso do i-ésimo tratamento.

Para avaliar os efeitos dos tratamentos foi usada análise de variância (ANOVA). Para as variáveis que não atenderam os pressupostos da ANOVA, foi utilizado o teste de distribuiçấo livre de Kruskal-Wallis $(\mathrm{p}<0,05)$.

\section{RESULTADOS E DISCUSSÃO}

Os valores médios para as variáveis físico-químicas da água náo apresentaram diferenças $(p>0,05)$ entre os tratamentos, estando dentro dos valores recomendados para cultivo do tambaqui (Kubitza 2003).

Náo houve diferença significativa $(p>0,05)$ para as variáveis de desempenho produtivo analisadas. Os valores médios para ganho de peso, comprimento final, consumo de ração, conversão alimentar, taxa de crescimento diário, eficiência aparente de conversão protéica, fator de condição e sobrevivência estão apresentados na Tabela 2.

Os resultados para o ganho de peso sugerem que o tambaqui é um peixe capaz de aproveitar bem raçóes contendo farinha de crueira de mandioca. Isso porque foi observado que os peixes submetidos aos tratamentos III, IV, V e II apresentaram valores ligeiramente maiores para esta variável $(30,6 \pm 4,1$ g; $29,0 \pm$ $1,9 \mathrm{~g} ; 28,5 \pm 6,7 \mathrm{~g}$ e $27,8 \pm 5,1 \mathrm{~g}$, respectivamente), quando comparados aos peixes dos tratamentos controle e I $(24,8 \pm$ $7,5 \mathrm{~g}$ e $23,8 \pm 8,1 \mathrm{~g}$, respectivamente). Pode-se explicar este fato pelo maior consumo de ração que os peixes dos quatro primeiros tratamentos mencionados apresentaram $(33,0 \pm 2,8$ g; $30,5 \pm 5,8 \mathrm{~g} ; 30,8 \pm 3,7 \mathrm{~g} \mathrm{e} 28,9 \pm 6,6 \mathrm{~g}$, respectivamente), quando comparados aos peixes dos dois últimos $(25,5 \pm 2,2$ g e 26,6 $\pm 3,4$ g, respectivamente).

Estes resultados concordam com os obtidos por Gallego $e t$ al. (1994) que avaliaram a utilização de farinha de mandioca, amido de trigo, maltodextrina de milho e amido de milho pré-gelatinizado em raçóes para enguia européia (Anguilla anguilla). Estes autores observaram que essa espécie aproveitou bem a farinha de mandioca, a qual promoveu taxas de crescimento superiores ao amido de milho e as outras fontes

Tabela 2 - Desempenho de juvenis de tambaqui (Colossoma macropomum) alimentados com diferentes níveis de substituição do milho pela farinha de crueira de mandioca (média e desvio padrão)1

\begin{tabular}{lcccccc}
\hline \multirow{2}{*}{ Parâmetros } & \multicolumn{5}{c}{ Níveis de substituição (\%) } \\
\cline { 2 - 7 } & 0 & 20 & 40 & 60 & 80 & 100 \\
\hline PI (g) & $6,6 \pm 0,1$ & $6,6 \pm 0,1$ & $6,6 \pm 0,1$ & $6,6 \pm 0,1$ & $6,7 \pm 0,1$ & $6,6 \pm 0,1$ \\
PF (g) & $31,4 \pm 7,4$ & $30,4 \pm 9,6$ & $34,4 \pm 6,3$ & $37,2 \pm 6,5$ & $35,7 \pm 2,5$ & $35,1 \pm 6,7$ \\
GP (g) & $24,8 \pm 7,5$ & $23,8 \pm 8,1$ & $27,8 \pm 5,1$ & $30,6 \pm 4,1$ & $29,0 \pm 1,9$ & $28,5 \pm 6,7$ \\
CF (cm) & $9,4 \pm 0,8$ & $9,1 \pm 1,2$ & $9,79 \pm 0,4$ & $10,1 \pm 0,6$ & $9,9 \pm 0,9$ & $9,7 \pm 0,7$ \\
CR (g) & $25,5 \pm 2,2$ & $26,6 \pm 3,4$ & $28,9 \pm 6,6$ & $33,0 \pm 2,8$ & $30,5 \pm 5,8$ & $30,8 \pm 3,7$ \\
CA & $1,0 \pm 0,2$ & $1,1 \pm 0,1$ & $1,0 \pm 0,1$ & $1,1 \pm 0,0$ & $1,1 \pm 0,0$ & $1,1 \pm 0,1$ \\
TCD (\%) & $1,6 \pm 0,3$ & $1,5 \pm 0,4$ & $1,8 \pm 0,2$ & $2,0 \pm 0,2$ & $1,8 \pm 0,1$ & $1,8 \pm 0,2$ \\
CP (\%) & $7,8 \pm 2,7$ & $6,4 \pm 1,4$ & $8,3 \pm 1,5$ & $7,9 \pm 0,8$ & $7,6 \pm 0,3$ & $8,3 \pm 1,6$ \\
K & $2,8 \pm 0,1$ & $2,8 \pm 0,1$ & $2,9 \pm 0,2$ & $3,0 \pm 0,1$ & $3,0 \pm 0,0$ & $3,0 \pm 0,1$ \\
S (\%) & 100 & 100 & 100 & 100 & 100 & 100 \\
\hline
\end{tabular}

Peso médio inicial (PI), peso médio final (PF), ganho de peso (GP), comprimento final (CF), consumo de ração (CR), conversão alimentar (CA), taxa de crescimento diário (TCD), conversão protéica (CP), fator de condição (K), sobrevivência (S)

${ }^{1}$ Valores nẫo diferem entre si (ANOVA, $\left.p>0,05\right)$. 
de carboidratos avaliadas. Segundo eles, isso pode ser explicado pelo fato da raçáo com farinha de mandioca apresentar boa aceitabilidade pela espécie.

Boscolo et al. (2002) verificaram que é possível substituir totalmente o milho pela farinha de varredura de mandioca, sem comprometimento da variável ganho de peso para tilápia do Nilo (Oreochromis niloticus). Para estes autores, a mandioca apresenta efeito aglutinante, sendo uma característica favorável às raçôes aquícolas, reduzindo a dissolução da ração na água e conseqüente a perda de nutrientes por lixiviaçáo, proporcionando melhor aproveitamento da ração pelo animal. Este fato também foi mencionado por Cantelmo et al. (2002) e Seixas et al. (1997).

Concordam, ainda, com os resultados encontrados por Seixas et al. (1997), que avaliaram o efeito aglutinante do farelo de mandioca em raçóes para pós-larvas de camarão (Macrobrachium rosembergii), constatando melhores resultados de ganho de peso nos animais alimentados com raçóes contendo a mandioca como aglutinante quando comparados com outros alimentos que apresentam essa característica, como: melaço seco, farinha de trigo e um aglutinante comercial. Para os autores, esse resultado pode ser explicado pelo fato da raçáo com farinha de mandioca apresentar menor lixiviação dos nutrientes. Por outro lado, Souza et al. (2008) avaliaram o desenvolvimento do tambaqui (Colossoma macropomum) em área de várzea testando três tratamentos: T1) ração industrial extrusada (100\%); T2) raçáo industrial extrusada parcelada com massa de mandioca branca $(50 \%$ de raçáo industrial + $50 \%$ massa de mandioca branca) e T3) massa mandioca branca $(100 \%)$. Ao final do experimento foi observado que os peixes do $\mathrm{T} 1$ apresentaram um maior crescimento, porém os peixes do T2 apresentaram um crescimento bastante satisfatório, não havendo diferença expressiva entre esses dois tratamentos. Já os peixes do T3 tiveram o desenvolvimento comprometido. Estes autores concluíram que este resultado pode ser explicado pela baixa quantidade de proteína e alta quantidade de energia encontrada na massa da mandioca.

Os resultados para a variável consumo de ração nesta pesquisa, corroboram com os encontrados por Gallego et al. (1994) que verificaram resultado semelhante ao trabalharem com enguia européia (Anguilla anguilla) alimentadas com raçóes contendo farinha de mandioca. Estes autores observaram maiores consumos de ração por esta espécie quando alimentadas com dietas contendo farinha de mandioca. Este fato também foi observado no trabalho de Seixas et al. (1997).

Boscolo et al. (2002) não verificaram diminuição no consumo de raçáo pela tilápia do Nilo (Oreochromis niloticus), com níveis crescentes de inclusáo de farinha de varredura de mandioca em substituiçáo ao milho. Concordam também com Lacerda et al. (2005) que não encontraram problemas quanto a aceitabilidade da carpa capim por raçôes contendo níveis de substituição do milho pelo farelo de mandioca.

Os valores para conversão alimentar aparente encontrados neste estudo (1,1 $\pm 0,2$-Tabela 2$)$ evidenciam que o Colossoma macropomum possui grande capacidade em aproveitar bem alimentos de origem vegetal. Estes valores são considerados baixos para o cultivo do tambaqui e estáo dentro da faixa ideal para cultivo de peixes, que é de 0,9 a 1,8 (Medri et al. 2005).

Os valores para taxa de crescimento diário neste estudo $(1,5 \pm 0,4$ a $2,0 \pm 0,2)$ estão de acordo com o observado por Santos et al. ( 2010) $(1,76 \pm 0,25)$ ao alimentarem juvenis de tambaqui, após privação alimentar, com ração contendo $28 \%$ de proteína bruta. Estes resultados demonstram menor eficiência dos peixes deste experimento em aproveitar a proteína da dieta, já que as raçóes contendo farinha de crueira de mandioca em substituiçáo ao milho possuem 36\% de proteína bruta. Isso pode ser explicado devido a capacidade dos peixes em crescer mais rapidamente que o normal (crescimento compensatório) após um período de restrição ou privação alimentar, recuperando o peso original ou aumentando a taxa de crescimento (Jobling et al. 1993; Nicieza e Metcalfe 1997).

Os resultados médios para variável fator de condição encontrados neste trabalho $(2,8 \pm 0,1$ a $3,0 \pm 0,1)$ corroboram com os resultados encontrados por Ituassú et al. (2004) (2,74 $\pm 0,02$ ) que estudaram o desenvolvimento de $C$. macropomum sob privação alimentar de 14 dias e realimentados por 46 dias com raçáo contendo $36 \%$ de proteína bruta. Porém são superiores aos resultados encontrados por Tavares-Dias et al. (2008) $(0,79$ a 1,25), que alimentaram juvenis de tambaqui com ração farelada contendo $34 \%$ de proteína bruta e, posteriormente, com ração peletizada contendo $28 \%$ de proteína bruta . Estes autores atribuíram esse baixo fator de condição possivelmente ao fato de alguns indivíduos terem apresentado menor peso, quando comparados a outros de mesmo comprimento, indicando possivelmente uma alteraçáo na atividade alimentar destes peixes, no viveiro. $\mathrm{O}$ que não foi verificado no presente estudo.

Não houve mortalidade dos juvenis de tambaqui durante o período experimental. Isso evidencia que os diferentes níveis de substituição do milho pela farinha de crueira de mandioca não afetaram a sobrevivência desta espécie. Algumas variedades de mandioca apresentam, em sua composição, os glicosídeos cianogênicos linamarina e lotaustralina, que liberam o ácido cianídrico, composto extremamente tóxico. Felizmente este composto é termolábil, sendo inativado durante o processamento (Cardoso Júnior et al. 2005).

Os resultados encontrados neste trabalho concordam com Boscolo et al. (2002), ao alimentar alevinos de tilápia do Nilo (Oreochomis niloticus) com raçôes contendo níveis crescentes de substituição do milho por farinha de varredura de mandioca. Para estes autores, a farinha de varredura de 
mandioca não apresentou problemas quanto a aceitabilidade pela tilápia do Nilo. Mencionaram também que a inclusão deste alimento não implicou em desbalanço nutricional das raçôes avaliadas, visto que foram formuladas com base em nutrientes digestíveis.

Os valores de desempenho produtivo analisados neste trabalho indicam que a farinha de crueira de mandioca é um alimento com potencial de uso em raçôes para juvenis de tambaqui. $\mathrm{O}$ comportamento das variáveis zootécnicas observados neste estudo pode estar relacionado ao hábito alimentar da espécie, uma vez que, de acordo com Melo et al. (2001), o tambaqui é caracterizado como onívoro, podendo aproveitar uma ampla gama de alimentos vegetais, sendo que carboidratos são itens frequentes na sua dieta.

A composição centesimal das carcaças dos peixes no início e no fim do experimento está apresentada na Tabela 3. Não foram encontradas diferenças significativas $(p>0,05)$ entre os tratamentos para matéria seca, proteína bruta e cinza. Entretanto, diferenças significativas $(\mathrm{p}<0,05)$ foram encontradas entre os tratamentos II e $\mathrm{V}$ para extrato etéreo. do tratamento $\mathrm{V}(11,5)$, quando comparada com a relaçáo energia: proteína do tratamento II $(11,1)$ sugere que a energia excedente fornecida aos peixes foi anabolizada para fins energéticos através da lipogênese, aumentando a deposiçăo de gordura corporal.

Resultado semelhante foi encontrado por Bomfim et al. (2005) que determinaram a exigência de proteína bruta e energia digestível em dietas para alevinos de curimbatá (Prochilodus affins), concluindo que peixes alimentados com dietas contendo maior nível energético apresentaram maior ganho de gordura corporal que aqueles alimentados com dietas contendo menor nível energético. Para estes autores, os peixes alimentados com baixos níveis de proteína utilizaram a energia adicional da dieta para deposiçáo de gordura corporal. Também podemos citar os trabalhos de Cotan et al. (2006) para lambari tambiú (Astyanax bimaculatus), Sá e Fracalossi (2002) para piracanjuba (Brycon orbignyanus), Cyrino et al. (2000) para "black bass" (Micropterus salmoides) e de Gonçalves et al. (2009) para tilápia do Nilo (Oreochromis niloticus), que constataram aumento de extrato etéreo na

Tabela 3 - Percentual de umidade, proteína bruta, cinza e extrato etéreo no músculo dos tambaquis (Colossoma macropomum) nos diferentes tratamentos (média e desvio padrão)

\begin{tabular}{lccccc}
\hline \multirow{2}{*}{ Tratamento } & \multirow{2}{*}{ Inclusão de Crueira } & \multicolumn{4}{c}{ Composição centesimal } \\
\cline { 3 - 6 } & & Matéria seca & Proteína bruta & Cinza & Extrato etéreo \\
\hline Inicial & - & 21,4 & 61,0 & 13,2 & 15,9 \\
Controle & $0 \%$ & $27,3 \pm 0,3$ & $59,7 \pm 1,9$ & $12,5 \pm 1,5$ & $20,0 \pm 1,3 \mathrm{ab}$ \\
I & $20 \%$ & $28,2 \pm 1,1$ & $58,3 \pm 1,5$ & $13,9 \pm 1,1$ & $21,0 \pm 1,8 \mathrm{ab}$ \\
II & $40 \%$ & $27,4 \pm 1,2$ & $59,0 \pm 2,0$ & $14,2 \pm 0,3$ & $20,9 \pm 0,2 \mathrm{~b}$ \\
III & $60 \%$ & $28,5 \pm 3,6$ & $58,5 \pm 2,4$ & $13,5 \pm 1,4$ & $20,2 \pm 1,0 \mathrm{ab}$ \\
IV & $80 \%$ & $27,5 \pm 2,9$ & $58,0 \pm 1,2$ & $12,3 \pm 1,5$ & $22,8 \pm 2,7 \mathrm{ab}$ \\
V & $100 \%$ & $28,3 \pm 0,9$ & $58,2 \pm 1,1$ & $12,4 \pm 0,8$ & $22,8 \pm 1,5 \mathrm{a}$ \\
\hline
\end{tabular}

Médias seguidas de letras diferentes diferem entre si (Teste de Kruskal-Wallis $p<0,05$ ) Inicial = Análise centesimal média dos tambaquis no início do experimento.

No inicio do experimento, a composição corporal dos peixes foi de $61 \%$ de proteína bruta, $15,9 \%$ de extrato etéreo e $13,2 \%$ de cinzas. Ao final da pesquisa, observou-se uma diminuição para os valores de proteína bruta na carcaça dos peixes e um aumento na deposição de gordura corporal, em todos os tratamentos. Este fato poderia estar relacionado com a diminuiçẫo da atividade física dos peixes durante o período experimental, já que no início deste estudo, os animais estavam alojados em um viveiro, sendo, posteriormente, confinados em uma caixa plástica com capacidade para 350 litros, para realização deste trabalho.

Houve diferença significativa $(\mathrm{p}<0,05)$ entre os tratamentos II e V para deposição de gordura corporal. Estas diferenças podem ser explicadas por duas teorias: diferença na relaçáo energia: proteína ou aumento da concentraçáo de extrato etéreo na dieta. A maior relação energia: proteína da ração composição química da carcaça dos peixes alimentados com dietas contendo aumentos na relação energia:proteína.

Outra possibilidade para o maior acúmulo de gordura no músculo dos peixes alimentados com a ração do tratamento $\mathrm{V}$ é o maior teor de extrato etéreo evidenciado nesta raçáo $(4,4 \%)$, conforme apresentado na Tabela 1. Esse maior teor de extrato etéreo pode estar relacionado com o maior nível de inclusão de óleo de soja e farinha de carne e ossos nesta raçáo. Resultado semelhante foi encontrado por Lanna et al. (2004) que avaliaram os efeitos de diferentes níveis de fibra bruta e de óleo na composição química da carcaça de tilápias, concluindo que a maior inclusão de óleo à ração tem efeito significativo no depósito de gordura corporal. Também podemos citar os trabalhos de Melo et al. (2003) para jundiá (Rhamdia quelen) e de Sampaio et al. (2000) para tucunaré (Cichla sp.), que 
constataram aumento de lipídios na composiçáo química da carcaça dos peixes com dietas contendo níveis crescentes de lipídio.

Houve queda no custo de produção das rações com a inclusão da farinha de crueira de mandioca, conforme apresentado na Tabela 4 . A ração mais cara foi a controle $(\mathrm{R} \$$ $1,43 / \mathrm{kg})$, seguida da ração I $(\mathrm{R} \$ 1,38 / \mathrm{kg})$, ração II $(\mathrm{R} \$ 1,33$ $\left.\mathrm{kg}^{-1}\right)$, ração III $\left(\mathrm{R} \$ 1,28 \mathrm{~kg}^{-1}\right)$, ração IV $\left(\mathrm{R} \$ 1,25 \mathrm{~kg}^{-1}\right)$ e ração $\mathrm{V}\left(\mathrm{R} \$ 1,21 \mathrm{~kg}^{-1}\right)$, respectivamente. Isso ocorreu devido ao alto custo do milho quando comparado ao valor da farinha de crueira de mandioca, que é um subproduto.

Também houve tendência de queda no custo de produção do quilograma de peixe com a inclusão da farinha de crueira de mandioca nas raçóes. O quilograma de peixe mais barato foi do $\mathrm{V}(\mathrm{R} \$ 1,30)$. Já o quilograma mais caro foi do I ( $\mathrm{R} \$$ $1,54)$, seguido pelo controle ( $\mathrm{R} \$ 1,47)$, II e III $(\mathrm{R} \$ 1,38)$ e IV $(\mathrm{R} \$ 1,31)$, respectivamente.

Em cultivos comerciais de peixes, os gastos com a alimentação correspondem com a maior parte dos custos produtivos, podendo alcançar $80 \%$ dos custos totais. Isso ocorre devido ao elevado valor que os ingredientes e as raçóes alcançam no mercado. Isso fica bem evidente na regiáo amazônica, onde existe a necessidade de importação desses produtos, devido à baixa produtividade agrícola regional. Este fato dificulta a verticalizaçáo da piscicultura como correta e socialmente justa, atendendo aos preceitos de sustentabilidade (Caporal e Costabeber 2002).

Se um produtor rural da regiâo amazônica optasse pelo sistema semi-intensivo de criação de tambaqui, a produtividade média esperada seria em torno de 10 toneladas de peixe por hectare ao ano. Nessas condiçôes, o gasto com ração necessário para produzir o pescado seria de $\mathrm{R} \$ 14.700,00$ para a ração controle, $\mathrm{R} \$ 15.400,00$ para a ração I, $\mathrm{R} \$ 13.800,00$ para as raçôes II e III, R \$ 13.100,00 para a ração IV e $\mathrm{R} \$ 13.000,00$ para a ração V. Comparando o gasto com a ração controle e a ração $\mathrm{V}$, observa-se uma economia de $\mathrm{R} \$ 1.700,00$ por hectare de lâmina d'água. Isso corresponde a $12 \%$ de redução no custo de produçáo de tambaqui, referente a ração. Essa vantagem permitirá ao produtor ofertar um produto mais competitivo no mercado. Já o consumidor terá acesso a um produto de menor valor comercial.

Este resultado concorda com o obtido por Chabalin et al. (1992), que utilizou restos de feira na alimentaçáo do pacu (Piaractus mesopotamicus) uma espécie que tem necessidade nutricional semelhante ao tambaqui, e observou uma reduçáo de $55 \%$ no custo de produçáo. Concorda, ainda, com os resultados encontrados por Soares et al. (2000) para piavuçu Leporinus macrocephalus, que observaram redução dos custos com o aumento dos níveis de substituição da proteína do farelo

Tabela 4 - Custo das rações experimentais (R\$) / Tratamento

\begin{tabular}{|c|c|c|c|c|c|c|c|c|}
\hline Ingrediente & Un. & Valor Un.(R\$) & $\begin{array}{c}\text { Contr. } \\
(0 \%)\end{array}$ & $\begin{array}{c}1 \\
(20 \%) \\
\end{array}$ & $\begin{array}{c}\| \\
(40 \%)\end{array}$ & $\begin{array}{c}\text { III } \\
(60 \%)\end{array}$ & $\begin{array}{l}\text { IV } \\
(80 \%)\end{array}$ & $\begin{array}{c}\mathrm{V} \\
(100 \%)\end{array}$ \\
\hline Milho & $\mathrm{kg}$ & 0,84 & 25,52 & 20,16 & 15,12 & 10,08 & 5,04 & - \\
\hline $\begin{array}{l}\text { Farelo de crueira de } \\
\text { mandioca }\end{array}$ & $\mathrm{kg}$ & 0,10 & - & 0,60 & 1,20 & 1,80 & 2,40 & 3,00 \\
\hline Óleo de soja & $\mathrm{L}$ & 2,50 & 9,00 & 9,25 & 8,50 & 9,00 & 8,00 & 9,00 \\
\hline Farelo de soja & $\mathrm{kg}$ & 1,22 & 67,10 & 56,88 & 64,29 & 60,75 & 61,00 & 55,87 \\
\hline Farelo glúten de milho & kg & 1,20 & 2,40 & 2,40 & 4,32 & 8,40 & 8,40 & 12,00 \\
\hline Farinha de carne e ossos & $\mathrm{kg}$ & 1,40 & 4,20 & 4,20 & 4,20 & 4,20 & 4,20 & 5,60 \\
\hline Farinha de peixe & $\mathrm{kg}$ & 1,80 & 5,40 & 5,40 & 5,40 & 5,40 & 5,40 & 5,40 \\
\hline Fosfato bicálcico & $\mathrm{kg}$ & 1,20 & 2,40 & 3,36 & 3,36 & 2,76 & 2,76 & 2,52 \\
\hline DL-metionina & $\mathrm{kg}$ & 20,00 & 7,00 & 7,00 & 7,00 & 6,4 & 8,6 & 8,00 \\
\hline Premix & $\mathrm{kg}$ & 20,00 & 20,00 & 20,00 & 20,00 & 20,00 & 20,00 & 20,00 \\
\hline TOTAL (100 kg) & - & - & 143,02 & 138,25 & 133,39 & 128,79 & 125,80 & 121,39 \\
\hline Custo/kg de ração & - & - & 1,43 & 1,38 & 1,33 & 1,28 & 1,25 & 1,21 \\
\hline $\begin{array}{l}\text { Custo médio/ } \\
\text { kg de PV ganho }\end{array}$ & - & - & 1,47 & 1,54 & 1,38 & 1,38 & 1,31 & 1,30 \\
\hline
\end{tabular}

Valores unitários obtidos através de consultas no comércio de Manaus no mês de maio de 2011.

atividade economicamente sustentável nessa região. Por isso, é imprescindível que sejam estudados ingredientes alternativos com potencial de uso em raçóes para peixes na Amazônia. Tais ingredientes devem contribuir para o desenvolvimento de uma piscicultura regional economicamente viável, ambientalmente de soja pela proteína do farelo de canola. Também concorda com os resultados encontrados por Furuya et al. (1997) para tilápias Oreochromis niloticus, que observaram diminuição dos custos até o nível de $25,36 \%$ de inclusão do farelo de canola nas dietas. 
Entretanto, discorda com os resultados encontrados por Soares et al. (1998) para carpa capim Ctenopharyngodon idella, e por Galdioli et al. (2002) para curimbatá Prochilodus lineatus, que não verificaram diminuiçấo dos custos de produção com níveis crescentes de inclusăo de farelo de canola nas raçôes experimentais.

\section{CONCLUSÕES}

É viável a substituiçáo total do milho pela farinha de crueira de mandioca, em raçôes para juvenis de tambaqui, sem que haja comprometimento das variáveis de desempenho avaliadas neste trabalho.

A substituição total do milho pela farinha de crueira de mandioca proporcionou aumento na deposição de gordura corporal dos peixes. Essa substituiçáo resultou em reduçáo no custo de produçấo das raçóes e do tambaqui.

\section{AGRADECIMENTOS}

A Fundação de Amparo à Pesquisa do Estado do Amazonas - FAPEAM - pela bolsa de estudos e suporte financeiro para execução do projeto. Ao Programa de Pós-Graduação em Biotecnologia da Universidade Federal do Amazonas - UFAM pela oportunidade.

Ao Instituto Nacional de Pesquisas da Amazônia - INPA - pelo auxílio estrutural.

\section{BIBLIOGRAFIA}

Association of Official Analytical Chemists (AOAC), 1997. Official Methods of Analysis. 16th. Ed. Gaithersburg, USA: 1140pp.

Araújo-Lima, C.; Goulding, M. 1998. Os frutos do tambaqui: ecologia, conservação e cultivo na Amazônia. Tefé, AM: Sociedade Civil Mamirauá/CNPq. 187 pp.

Arbelaez-Rojas, G. A.; Fracalossi, D. M.; Fim, J. D. I. 2002. Composição corporal de tambaqui, Colossoma macropomum, e matrinxã, Brycon cephalus, em sistemas de cultivo intensivo, em igarapé, e semi-intensivo, em viveiros. Revista Brasileira de Zootecnia, 31: 1059-1069.

Batista, V. S.; Petrere Júnior, M. 2003. Characterization of the commercial fish production landed at Manaus, Amazonas State, Brazil. Acta Amazonica, 33: 53-66.

Batista V. S.; Isaac V. J.; Viana J. P. 2004. Exploração e manejo dos recursos pesqueiros da Amazônia, p. 63-151. In: Ruffino, M. L. (Org.). A pesca e os recursos pesqueiros na Amazônia. IBAMA, Manaus, Amazonas.

Bellaver, C.; Fialho, E. T.; Protas, J. F. S. 1985. Radícula de malte na alimentação de suínos em crescimento e terminação. Pesquisa Agropecuária Brasileira, 20: 969-974.

Boonyaratpalin, M.; Suraneiranat, P.; Tunpibal, T. 1998. Replacement of fish meal with various types of soybean products in diets for the Asian seabass, Lates calcarifer. Aquaculture, 161: 67-78.
Bomfim, M. A. D.; Lanna, E. A. T.; Serafini, M. A.; Ribeiro, F. B.; Pena, K. S. 2005. Proteína bruta e energia digestível em dietas para alevinos de curimbatá (Prochilodus affins). Revista Brasileira de Zootecnia, 34: 1795-1806.

Boscolo, W.; Hayashi, C.; Meurer, F. 2002. Digestibilidade aparente da energia e nutrientes de alimentos convencionais e alternativos para tilápia do Nilo (Oreochromis niloticus). Revista Brasileira de Zootecnia, 31: 1-9.

Cantelmo, O. A.; Pezzato, E. L.; Barros, M. M.; Pezzato, A. C. 2002. Características físicas de dietas para peixes confeccionadas com diferentes aglutinantes. Acta Scientiarum, 24: 949-955.

Caporal, R. F.; Costabeber, A. J. 2002. Análise multidimensional da sustentabilidade. Agroecologia e Desenvolvimento Rural Sustentável, 3: 71-84.

Cardoso Júnior, N. S.; Viana, A. E. S.; Matsumoto, S. N.; Sediyama, T.; Amaral, C. L. F.; Pires, A. J. V.; Ramos, P. A. S. 2005. Efeito do nitrogênio sobre o teor do ácido cianídrico em plantas de mandioca. Acta Scientiarum, 27: 603-610.

Cereda, M. P. 1994. Caracterização dos resíduos da industrialização da mandioca, p. 11-50. In: Cereda, M.P. (Eds). Residuos da industrialização da mandioca. São Paulo.

Chabalin, E.; Palhares, F. J. V.; Ferraz, J. A.; Neves, E. M. 1992. Viabilidade econômica da utilização de resíduos hortifrutigranjeiros na criação do pacu, Piaractus mesopotamicus, em gaiolas. Boletim técnico do CEPTA, 5: 23-29.

Cheng, Z. J.; Hardy, R. W.; Usry, J. L. 2003. Effects of lysine supplementation in plant protein-based diets on the performance of rainbow trout Oncorhynchus mykiss and apparent digestibility coefficients of nutrients. Aquaculture, 215: 255-265.

Cotan, J. L. V.; Lanna, E. A. T.; Bomfim, M. A. D.; Donzele, J. L.; Ribeiro, F. B.; Serafini, M. A. 2006. Níveis de energia digestível e proteína bruta em raçóes para alevinos de lambari tambiú. Revista Brasileira de Zootecnia, 35: 634-640.

Cyrino, J. E. P.; Portz, L.; Martino, R. C. 2000. Retenção de proteína e energia em juvenis de "black bass" Micropterus salmoides. Scientia Agricola, 57: 609-616.

Furuya, V. R. B.; Hayashi, C.; Furuya, W. M. 1997. Farelo de canola na alimentaçáo da tilápia do Nilo (Oreochromis niloticus L.), durante o período de reversão do sexo. Revista Brasileira de Zootecnia, 26: 1067-1073.

Galdioli, E. M.; Hayashi, C.; Soares, C. M.; Furuya, V. R. B.; Faria, A. C. A. 2002. Substituição da Proteína do Farelo de Soja pela Proteína do Farelo de Canola em Raçóes para Alevinos de Curimbatá (Prochilodus lineatus v.). Revista Brasileira de Zootecnia, 31: 552 - 559.

Gallego, M. G.; Bazoco, J.; Akharbach, H. 1994. Utilization of different carbohydrates by the European eel (Anguilla anguilla). Aquaculture, 124: 638 - 644.

Gomes, L. C.; Chippari-Gomes, A. R.; Lopes, N. P.; Roubach, R.; Araújo - Lima, C. A. R. M. 2001. Efficacy of benzocaine as an anesthetic in juvenile tambaqui, Colossoma macropomum. Journal of the World Aquaculture society, 32: 426 - 431. 
Gonçalves, G. S.; Pezzato, L. E.; Barros, M. M.; Hisano, H.; Rosa, M. J. S. 2009. Níveis de proteína digestível e energia digestível em dietas para tilapias-do-nilo formuladas com base no conceito de proteína ideal. Revista Brasileira de Zootecnia, 38: 2289-2298.

Graef, E. W. 1995. As espécies de peixes com potencial para criação no Amazonas, p. 29-43. In: Val, L. A. (Eds). Criando peixes na Amazônia. Instituto Nacional de Pesquisas da Amazônia, Manaus, Amazonas.

Guimarães, I. G.; Pezzato, L. E.; Barros, M. M.; Tachibana, L.; Fernandes, R. N. 2011. Digestibilidade do amido e disponibilidade de Ca e P em alimentos energéticos extrusados para a tilápia do Nilo (Oreochromis niloticus). Ciência Animal Brasileira, 12: 415-419.

Hancz, C. 1993. Performance of the Amazonian tambaqui, Colossoma macropomum, in pond polyculture. Aquaculture, 12: 245 - 254.

Ituassú, D. R; Santos, G. R. R.; Roubach, R.; Pereira-filho, M. 2004. Growth of tambaqui submitted to different feed deprivation periods. Pesquisa Agropecuária Brasileira, 39: 1199-1203.

Jobling, M.; Jorgensen, E. H; Siikavuopio, S. I. 1993. The influence of previous feeding regime on the compensatory growth response of maturing and immature Arctic charr, Salvelinus alpinus. Journal of Fish Biology, 43: 409-419.

Kubitza, F. 2003. Qualidade da água no cultivo de peixes e camaröes. Jundiaí. SP: Jundiaí. 229 pp.

Lanna, E. A. T.; Pezzato, L. E.; Furuya, W. M.; Vicentini, C. A.; Cecon, P. R. Barros, M. M. 2004. Fibra bruta e óleo em dietas praticas para alevinos de tilápia do Nilo (Oreochromis niloticus). Revista Brasileira de Zootecnia, 33: 1-12.

Lacerda, C. H. F.; Hayashi, C.; Soares, C. M.; Boscolo, W. R; Kavata, L. C. B. 2005. Farelo de mandioca (Manihot esculenta) em substituição ao milho (Zea mays) em raçôes para alevinos de carpa capim (Ctenopharyngodon idella). Acta Scientiarum, 27: 241-245.

Medri, V.; Medri, W.; Filho, M. C. 2005. Desempenho de tilápias nilóticas (Oreochromis niloticus) alimentadas com diferentes níveis de proteína de levedura de destilaria em tanques-rede. Acta Scientiarum, 27: 221-227.

Melo, L. A. S.; Izel, A. C. U.; Rodrigues, F. M. 2001. Criação de tambaqui (Colossoma macropomum) em viveiros de argilalbarragens no Estado do Amazonas. Embrapa Amazônia Ocidental. 30 pp.

Melo, J. F. B.; Boijink, C. L.; Radünz Neto, J. R. 2003. Efeito da alimentação na composição química da carcaça do jundiá (Rhamdia quelen). Biodiversidade Pampeana, 1: 12-23.

Mori-Pinedo, L. A.; Pereira-Filho, M.; Oliveira-Pereira, M. I. 1999. Substituição do fubá de milho (Zea mays, L.) por farinha de pupunha (Bactris gasipaes, H.B.K.) em raçôes para alevinos de tambaqui (Colossoma macropomum, Cuvier, 1818). Acta Amazonica, 29: 447-453.

NATIONAL RESEARCH COUNCIL - NRC. 1993. Nutrients requirements of warmwater fishes and shellfishes. Washington: Academy Press. 102 pp.
Nicieza, A. G; Metcalfe, N. B.1997. Growth compensatory in juvenile Atlantic Salmon: Responses to depressed temperature and food availability. Ecology, 78: 2385-2400.

Padua, D. M. C; Silva, P. C.; Padua, J. T.; Urbinat, E. C. 2009. Respostas fisiológicas do pacu (Piaractus mesopotamicus), alimentado com rama de mandioca (Manihot esculenta) na ração. Ciência Animal Brasileira, 10: 385-396.

Pereira-Filho, M. 1995. Alternativas para a alimentação de peixes em cativeiro, p. 75-82. In: Val, L. A. (Eds). Criando peixes na Amazônia. Instituto Nacional de Pesquisas da Amazônia, Manaus, Amazonas.

Rolim, P. R. 1995. A infra-estrutura básica para criação de peixes no Amazonas, p. 7-16. In: Val, L. A. (Eds). Criando peixes na Amazônia. Instituto Nacional de Pesquisas da Amazônia, Manaus, Amazonas.

Roubach, R.; Saint-Paul, U. 1994. Use fruits and seeds from Amazonian inundated forest in feeding trials with Colossoma macropomum (Cuvier, 1818) (Pisces, Characidae). Journal Applied Ichthyology, 101: 34-140.

Sá, M. V. C.; Fracalossi, D. M. 2002. Exigência protéica e relação energia/proteína para alevinos de piracanjuba (Brycon orbignyanus). Revista Brasileira de Zootecnia, 31: 1-10.

Sampaio A. M. B.; Kubitza, F.; Cyrino, J. E. P. 2000. Relação energia: proteína na nutrição do tucunaré. Scientia Agrícola, 57: 1-13.

Santos, E. L.; Ludke, L. M.; Ramos, A. M.; Barbosa, J. M.; Ludke, J. B.; Rabelo, C. B. 2009. Digestibilidade de subprodutos da mandioca pela tilápia do Nilo. Revista Brasileira de Ciência Rural, 4: $358-362$.

Seixas, J. T. E; Santiago A. M. 1997. Avaliação do desempenho de pós-larvas de camarão de água doce (Macrobachium rosembergii de Man) alimentados com dietas contendo diferentes aglutinantes. Revista Brasileira de Zootecnia, 26: 638-644.

Silva, P. C.; Mesquita de, A. J.; Palma, C. S.; Oliveira de, A. N. 1991. Aspectos biométricos, bacteriológicos e físico-químicos do tambaqui (Colossoma macropomum) criado em consórcio com suínos. Revista Brasileira de Zootecnia, 5: 6-8.

Soares, C. M.; Hayashi, C.; Furuya, V. R. B.; Furuya, W. M.; Galdiolo, E. M. 2000. Substituição parcial e total da proteína do farelo de canola na alimentação de alevinos de piavuçu (Leporinus macrocephalus, L.). Revista Brasileira de Zootecnia, 29: 15-22.

Soares, C. M.; Hayashi, C.; Furuya, V. R. B. 1998. Farelo de canola na alimentaçấo de alevinos de carpa-capim (Ctenopharyngodon idella V.). Acta Scientiarum, 20: 395-400.

Souza A. S.; Souza, R. A. L.; Melo, N. F. A.; Mourão Filho, M. M.; Palheta, G. D. A; Nascimento, A. M. 2008. Desenvolvimento do tambaqui, Colossoma macropomum, cuvier 1818 (Pisces, Serrasalmidae) em área de várzea utilizando-se massa de mandioca branca, manihot esculenta, como alimentação alternativa. In: SEMINÁRIO INTERNACIONAL - AMAZÔNIA E FRONTEIRAS DO CONHECIMENTO, 1., 2008, Belém. Belém: Naea, 2008. p. 1 - 21. 
Tagliari, P. S. 1996. Agro-indústria de mandioca de mandioca: desafios para os pequenos empresários. Agropecuária Catarinense, 9: $37-42$.

Tavares-Dias, M.; Marcon, J.; Lemos, J. R. G.; Fim, J. D. I.; Affonso E. G.; Ono, E. A. 2008. Índices de condição corporal em juvenis de Brycon amazonicus (Spix e Agassiz, 1829) e Colossoma macropomum (CUVIER, 1818) na Amazônia. Boletim do Instituto de Pesca, 34: 197-204.

Val A. L.; Silva M. N. P.; Almeida-Val V. M. F. 1998. Hypoxia adaptation in fish of the Amazon: a never-ending task. South African Journal of Zoology, 33: 107-114.
Val, A. L. 1995. A criação de peixes na Amazônia: um futuro promissor, p. 1-5. In: Val, L. A. (Eds). Criando peixes na Amazônia. Instituto Nacional de Pesquisas da Amazônia, Manaus, Amazonas.

Ximenes-Carneiro, A. R. 1991. Elaboração e uso de ensilado biológico de pescado na alimentação de alevinos de tambaqui Colossoma macropomum (Cuvier, 1818). Dissertação de mestrado, Instituto Nacional de Pesquisas da Amazônia/Fundação Universidade Federal do Amazonas, Manaus, Amazonas. 81pp.

Recebido em: 31/01/2012

Aceito em:14/06/2012 